\title{
ADVANCED SURFACE MODIFICATION OF INDIUM TIN OXIDE FOR IMPROVED CHARGE INJECTION IN ORGANIC DEVICES
}

$$
\text { by }
$$

Eric L. Hanson, Jing Guo, Norbert Koch,$\dagger$ Jeffrey Schwartz* and Steven L. Bernasek Department of Chemistry, Princeton University, Princeton, NJ 08544-1009

†Institut für Physik, Humboldt-Universität zu Berlin, D-12489 Berlin, Germany

*FAX: +1 (609) 258 2383; email: jschwartz@princeton.edu

\section{Supporting Information}

QCM frequency change determination of 4TP surface loading on ITO, showing 7 cycles of deposition (D) and rinsing (R).

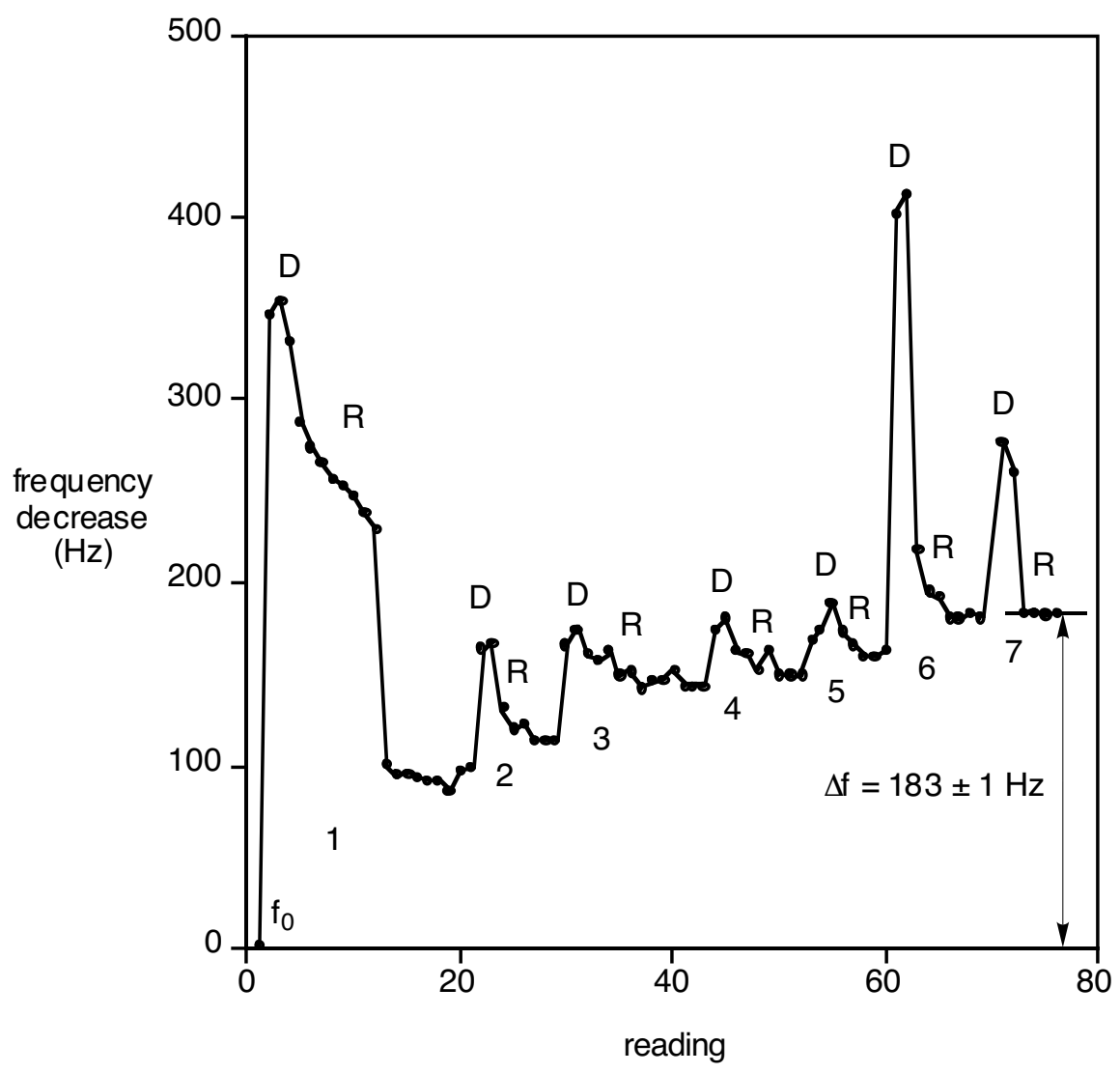

